Corrigendum

\title{
Corrigendum to "Neuroprotective Effects of Polydeoxyribonucleotide in a Murine Model of Cadmium Toxicity"
}

\author{
Herbert R. Marini $\left(\mathbb{D},{ }^{1}\right.$ Domenico Puzzolo $\left(\mathbb{D},{ }^{2}\right.$ Antonio Micali $\left(\mathbb{D},{ }^{2}\right.$ Elena Bianca Adamo, ${ }^{2}$ \\ Natasha Irrera $\left({ }^{1}{ }^{1}\right.$ Antonina Pisani, ${ }^{2}$ Giovanni Pallio $₫{ }^{1},{ }^{1}$ Vincenzo Trichilo, ${ }^{1}$ \\ Consuelo Malta, ${ }^{2}$ Francesco Squadrito $\mathbb{D}^{1},{ }^{1}$ Domenica Altavilla $\mathbb{D}^{2},{ }^{2}$ and Letteria Minutoli ${ }^{1}$ \\ ${ }^{1}$ Department of Clinical and Experimental Medicine, University of Messina, Messina, Italy \\ ${ }^{2}$ Department of Biomedical and Dental Sciences and Morphofunctional Imaging, University of Messina, Messina, Italy
}

Correspondence should be addressed to Antonio Micali; amicali@unime.it

Received 26 November 2018; Accepted 2 December 2018; Published 13 December 2018

Copyright (C) 2018 Herbert R. Marini et al. This is an open access article distributed under the Creative Commons Attribution License, which permits unrestricted use, distribution, and reproduction in any medium, provided the original work is properly cited.

In the article titled "Neuroprotective Effects of Polydeoxyribonucleotide in a Murine Model of Cadmium Toxicity" [1], Dr. Alessandra Bitto was incorrectly included as an author. The corrected authors' list is shown above. In addition, the Acknowledgments section should be updated as follows:

The investigation was granted by a departmental funding. The authors thank Dr. Alessandra Bitto for the helpful discussions and thank Mister Sebastiano Brunetto of the Department of Biomedical Sciences, University of Messina, for his dedicated technical expertise.

\section{References}

[1] H. R. Marini, D. Puzzolo, A. Micali et al., "Neuroprotective effects of polydeoxyribonucleotide in a murine model of cadmium toxicity," Oxidative Medicine and Cellular Longevity, vol. 2018, Article ID 4285694, 9 pages, 2018. 


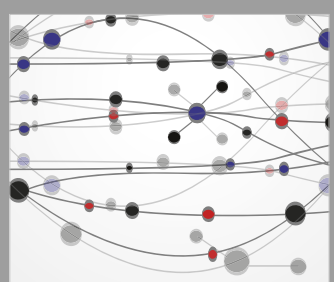

The Scientific World Journal
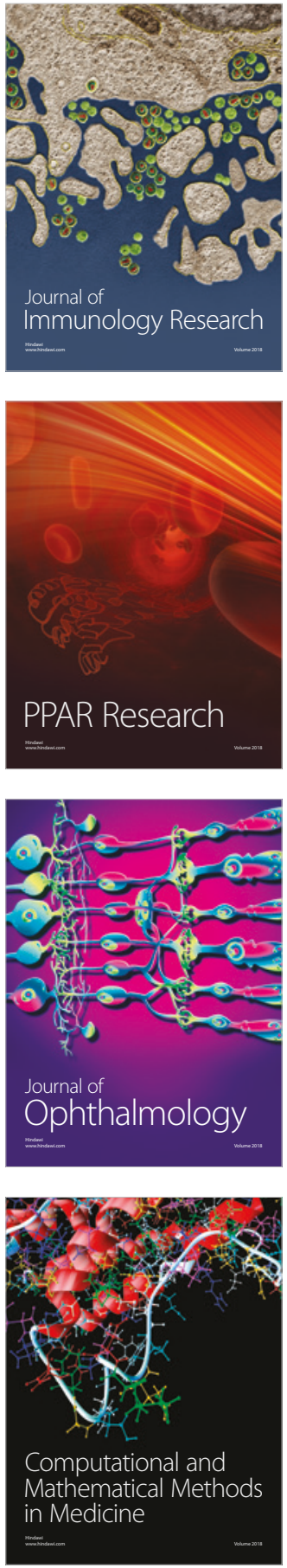

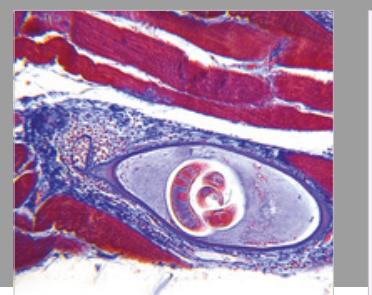

Gastroenterology Research and Practice

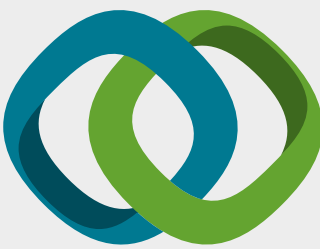

\section{Hindawi}

Submit your manuscripts at

www.hindawi.com
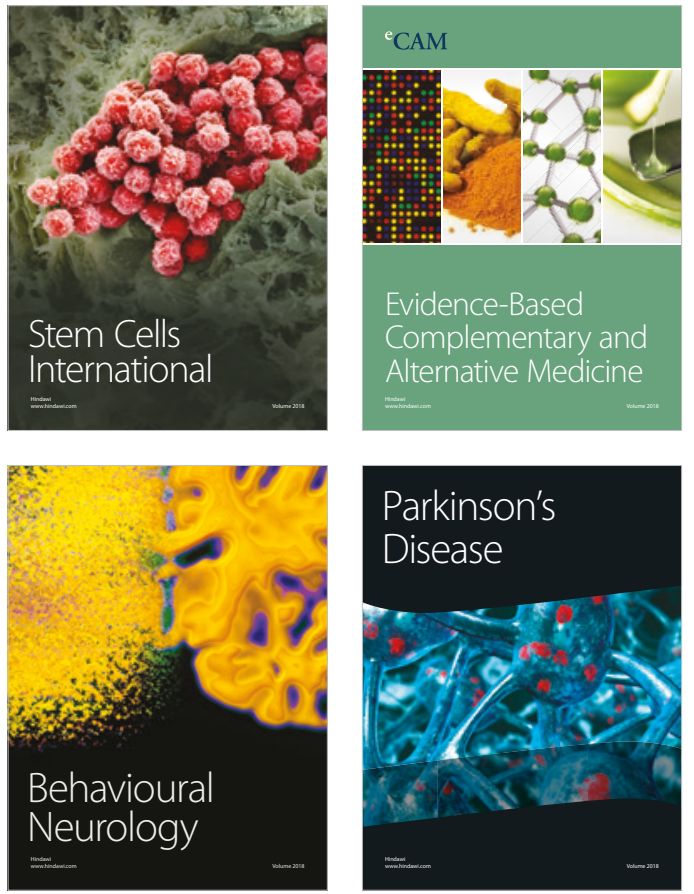

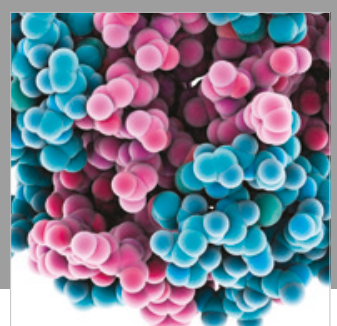

ournal of

Diabetes Research

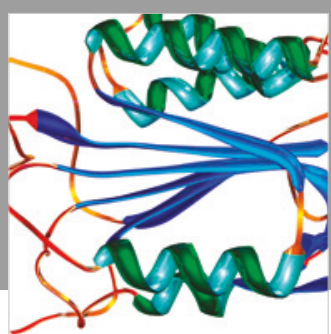

Disease Markers
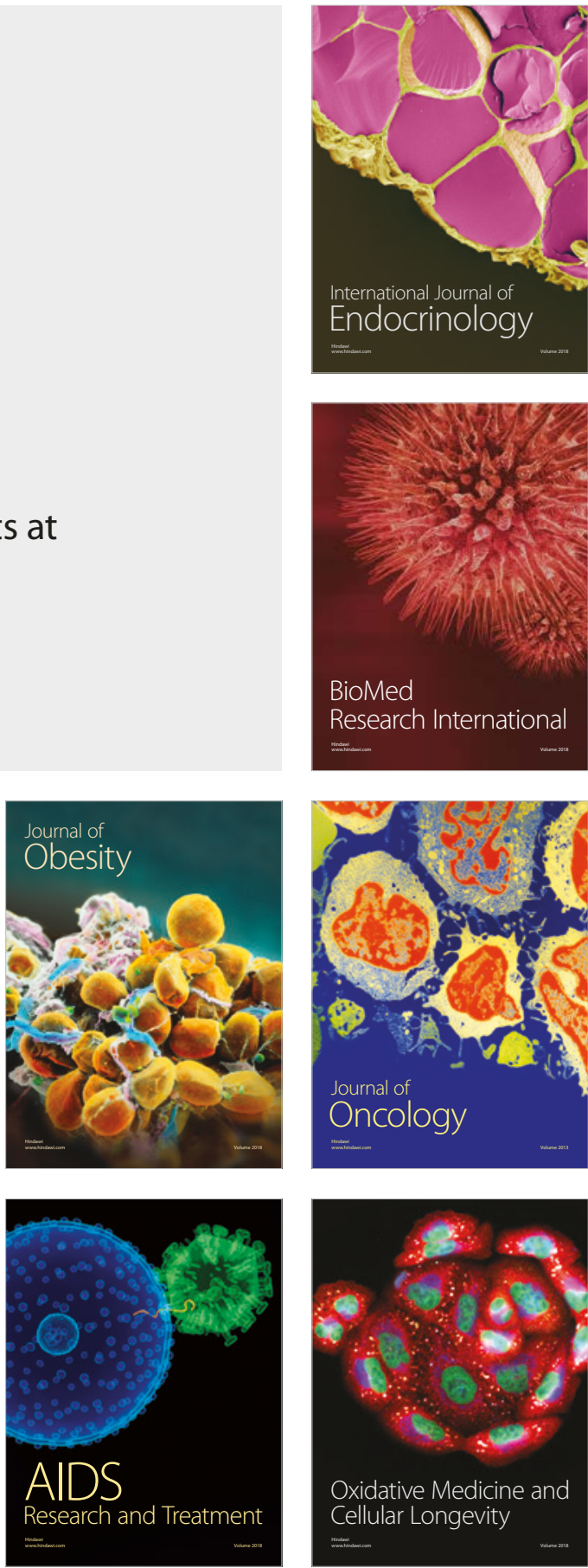